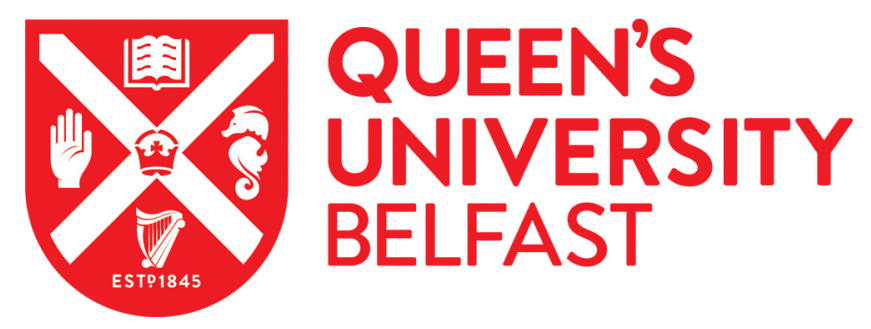

\title{
'Very difficult for an ordinary guy': Factors influencing the quality of treatment decision-making amongst men diagnosed with localised and locally advanced prostate cancer: findings from a UK-wide mixed methods study
}

Wagland, R., Nayoan, J., Matheson, L., Rivas, C., Brett, J., Downing, A., Wilding, S., Butcher, H., Gavin, A., Glaser, A. W., \& Watson, E. (2018). 'Very difficult for an ordinary guy': Factors influencing the quality of treatment decision-making amongst men diagnosed with localised and locally advanced prostate cancer: findings from a UK-wide mixed methods study. Patient Education and Counseling. https://doi.org/10.1016/j.pec.2018.12.004

Published in:

Patient Education and Counseling

Document Version:

Peer reviewed version

Queen's University Belfast - Research Portal:

Link to publication record in Queen's University Belfast Research Portal

\author{
Publisher rights \\ (C) 2018 Elsevier B.V. All rights reserved \\ This manuscript version is made available under the CC-BY-NC-ND 4.0 license http://creativecommons.org/licenses/by-nc-nd/4.0/,which \\ permits distribution and reproduction for noncommercial purposes, provided the author and source are cited
}

\section{General rights}

Copyright for the publications made accessible via the Queen's University Belfast Research Portal is retained by the author(s) and / or other copyright owners and it is a condition of accessing these publications that users recognise and abide by the legal requirements associated with these rights.

Take down policy

The Research Portal is Queen's institutional repository that provides access to Queen's research output. Every effort has been made to ensure that content in the Research Portal does not infringe any person's rights, or applicable UK laws. If you discover content in the

Research Portal that you believe breaches copyright or violates any law, please contact openaccess@qub.ac.uk. 


\section{Authors' Copy}

'Very difficult for an ordinary guy': Factors influencing the quality of treatment decision-making amongst men diagnosed with localised and locally advanced prostate cancer: findings from a UKwide mixed methods study

Richard Wagland ${ }^{1}$

Johana Nayoan ${ }^{2}$

Lauren Matheson ${ }^{3}$

Carol Rivas ${ }^{4}$

Jo Brett ${ }^{3}$

Amy Downing ${ }^{5,6}$

Sarah Wilding ${ }^{5,6}$

Hugh Butcher ${ }^{7}$

Anna Gavin ${ }^{8}$

Adam W Glaser ${ }^{5,6}$

Eila Watson ${ }^{3}$

1. Faculty of Health Sciences, University of Southampton, Southampton, UK

2. Health Psychology Research Group, University College London, UK

3. Faculty of Health and Life Sciences, Oxford Brookes University, Oxford, UK

4. Social Science Research Unit, University College London (UCL), London, UK

5. Leeds Institute of Medical Research at St James's, University of Leeds, UK

6. Leeds Institute of Data Analytics, University of Leeds, Leeds, UK

7. Yorkshire Cancer Patient Forum, c/o Strategic Clinical Network and Senate, Yorkshire and The Humber, Harrogate, UK

8. Northern Ireland Cancer Registry, Centre for Public Health, Queen's University Belfast, Belfast, UK

Corresponding author: Dr Richard Wagland

Senior Research Fellow/ Lecturer, Faculty of Health Sciences, Building 67, Highfield, Southampton, SO17 1BJ

Tel: 02380597868

Email: R.Wagland@soton.ac.uk 


\section{Abstract}

Objectives: To explore the experience of treatment decision-making (TDM) amongst men diagnosed with stage 1-3 prostate cancer.

Methods: Mixed-methods study incorporating UK wide cross-sectional postal survey of men 18-42 months post-diagnosis and semi-structured interviews with a subsample $(n=97)$, including men who received both radical treatments and active surveillance. Interview data was analysed using a Framework approach.

Findings: Within the context of TDM, 'drivers' included men's preferences for decision-making responsibility or clinical direction, relative treatment intrusiveness or desire for excision, and work, personal and social life priorities; 'facilitators' were mechanisms such as shared decision-making utilised by clinicians to enact, but also sometimes challenge drivers. Drivers and facilitators can conflict, challenging patient empowerment. Men frequently undertook greater TDM responsibility than they desired, with no clinical recommendations; others reported receiving conflicting clinical recommendations. Information on potential side effects was often reported as inadequate. Unchallenged preferences, absence of clinical recommendations and inadequate preparation for side effects sometimes led to decision regret.

Conclusions: TDM should involve men exercising preferences and priorities in discussion with clinicians. Men are not empowered when required to take more TDM responsibility than desired or when their potentially inappropriate preferences are unchallenged. Clinicians should ensure patients do not receive conflicting recommendations.

Word count: Abstract: $200 \quad$ Manuscript: 3997

Key words: Prostate cancer; patient empowerment; treatment decision-making; patient-reported outcomes

Declarations of interest: none 


\section{INTRODUCTION}

Prostate cancer ( $\mathrm{PCa}$ ) is the most common form of cancer amongst men in the UK and developed countries, with 10 -year survival rates of $\geq 84 \%[1]$. The high probability of long-term survival makes health-related quality of life (HRQOL) a priority. Men diagnosed with localised (stage I-II) and locally advanced (stage III) PCa are often offered a range of potential treatment choices, including radical prostatectomy (RP), external beam radiotherapy (EBRT), brachytherapy (BT), adjuvant androgen deprivation therapy (ADT), active surveillance (AS), or combinations of these (i.e. EBRT and ADT). Newer treatments such as cryotherapy and high intensity focussed ultrasound (HIFU) have limited availability. The treatment decision-making (TDM) process for men diagnosed with PCa is particularly difficult, as current clinical and pathological features are limited in their ability to distinguish between inherently aggressive and indolent tumours[2], and there is currently no clear evidence to suggest one treatment is more effective than another[3].

The commonly available treatment options all have side effects that can significantly impact upon the HRQoL of men, and may persist long-term[4,5]. These include sexual and urinary dysfunction following RP, bowel dysfunction, loss of libido and urinary irritations following EBRT, and gynecomastia, mood disturbances, weight gain, penile shrinkage, loss of libido and hot flushes following ADT. While AS avoids or delays active treatment and associated physical side effects, it has nevertheless been associated with anxiety over non-treatment and potential disease progression, and increasing urinary obstructive symptoms[6]. It is unclear whether the benefits of AS outweigh potential negative effects of treatment[7,8]. While most patients who choose active treatment accept side effects as consequences of treatment, when multiple, equally effective treatments are available, each with negative side effects, TDM can be dominated by significant uncertainty and anxiety[5]. 
This study, part of a UK-wide, patient-reported outcome (PRO) survey entitled Life After Prostate Cancer Diagnosis (LAPCD)[9], explored the experience of TDM amongst men diagnosed with stage IIII prostate cancer.

\section{METHODS}

\subsection{STUDY DESIGN}

LAPCD is a UK-wide population based mixed-methods study, incorporating a national postal survey and semi-structured telephone interviews with a purposively selected subsample[9]. In England, 111 of 136 Trusts participated along with all Trusts/Health Boards in Northern Ireland, Scotland and

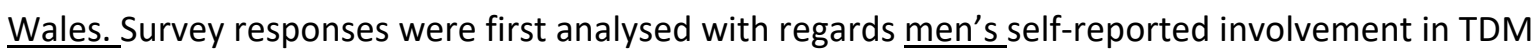
of and their experience then explored in greater depth through interviews. The research team worked in collaboration with a patient-user advisory group and clinical colleagues at all stages of the project.

\subsection{PARTICIPANTS AND SETTING}

Men alive 18-42 months following PCa diagnosis (ICD10 C61) in participating Trusts were identified through population-based cancer registries in England, Wales, Scotland and Northern Ireland, and mailed surveys from their treating Trust/Board. Completed surveys were returned to a survey provider, Picker Institute Europe, who managed the data. Men in England were surveyed December 2015-March 2016, and in Scotland, Northern Ireland and Wales July-October 2016.

Respondents indicated on the survey their willingness to be contacted and invited for interview. A purposive sampling framework was developed, stratified by treatment group (e.g. RP, EBRT, brachytherapy, ADT, and AS). We also included a range of men who indicated experience of either no problems or one or more physical (e.g. urinary incontinence, bowel problems and erectile dysfunction) and emotional problems (e.g. anxiety/depression). Participants included men from Black, Asian and Minority Ethnic groups and self-identified sexualities. Cross-sectional, semi- 
structured telephone interviews were conducted by four experienced researchers (JN, LM, CR and RW), across two universities in England between January-November 2016.

\subsection{MATERIALS}

The main LAPCD survey comprised eight sections, totalling 88 questions. Section Two "Your diagnosis and treatment" included a question about TDM involvement that asked patients: 'Do you think your views were taken into account when the team of doctors and nurses caring for you were discussing which treatment you should have?' Possible responses were: TDM1. 'Yes, definitely'; TDM2. 'Yes, to some extent'; TDM3. 'No, my views were not taken into account'; TDM4. 'I didn't know my treatment was being discussed by a team of doctors/nurses'; TDM5. 'Not sure/can't remember'. A version of this question was validated as part of the PICKER Patient Experience Questionnaire[10], and has subsequently been incorporated, albeit in slightly altered versions, in each iteration of the National Cancer Patient Survey[11]. Immediately following this question in the

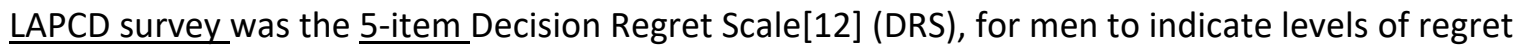
they felt regarding their treatment decision. These five items are combined to form a scale 0-100,

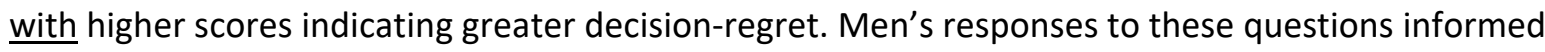
analysis of their interview data.

An interview topic guide was developed in collaboration with clinical colleagues and our patient/user group, and informed by previous evidence[13]. The guide comprised open-ended questions, each with several prompts. Amongst issues discussed, men were asked to describe their TDM experiences; how much information they had received about their condition, the extent to which they had wanted control or had felt in control of decision-making, whether they were treated as an equal partner in the process by clinicians and what influenced their treatment decisions.

\subsection{ANALYSIS}


For this analysis we explored the TDM process described by men during their interviews and compared these with the response they provided to the TDM question in the survey. Interviews were transcribed verbatim and data uploaded into Nvivo v.11.2[14], and analysed using FrameworkAnalysis; a matrix-based approach conducted through a series of stages $[15,16]$. The first stage involved familiarization, whereby researchers became immersed in the data and aware of key ideas and recurrent themes. Following each interview, researchers' summarised key issues discussed and shared these amongst the research team for discussion.

A thematic coding framework of emerging themes was then developed. An initial draft of the coding framework was tested against five interview transcripts. Four researchers (JN,CR,EW,RW) independently coded the same three transcripts, with codes then discussed. Several patient/user group members reviewed selected transcripts and provided feedback. The complete dataset was then indexed, identifying data that corresponded to particular themes. Double coding in Nvivo11 was conducted by three authors (CR, EW and RW) on 10\% of interviews, with final Kappa scores of $\geq 80 \%$ across all themes for all researchers. Indexed data was then arranged in charts/matrices of themes, and key ideas and themes summarized in the charts/matrices with relationships between them identified. Extracts are provided to illustrate themes in the Findings section, with clinical and demographic characteristics of participants and responses to TDM and DRS questions.

\subsection{Ethics}

The study received the following approvals: Newcastle and North Tyneside 1 Research Ethics Committee (15/NE/0036), Health Research Authority Confidentiality Advisory Group (15/CAG/0110), NHS Scotland Public Benefit and Privacy Panel (0516-0364), and NHS R\&D approval from Wales, Scotland and Northern Ireland.

\section{FINDINGS}


In total, $35,823 / 58,930(60.8 \%)$ men completed the survey. Of these, $26,808(74.8 \%)$ were diagnosed at stage I-III. Interviews were conducted with 97 men (stage I-III) from across the UK. Table 1 shows participants' demographic and treatment characteristics. The interview sample was younger than respondents to the survey only (mean 65.5 Vs. 71 years), more ethnically diverse, with a higher proportion of men on AS. Most interview participants were diagnosed at stage I $(46.4 \%, n=45)$, EBRT with ADT was the most common treatment option $(25.2 \%, n=26)$.

\subsection{SURVEY DATA}

Most study participants, both survey-only respondents and those interviewed (68.8\% vs. $69.0 \%$ ), indicated their views had 'definitely' been taken into account during the TDM process (Table 2). Further proportions of survey-only and interview participants (17.8\% vs. $24.7 \%)$, indicated their views were 'to some extent' taken into account, which might suggest they were not fully involved with TDM. Very few (3.3\% vs. $2.1 \%$ ) indicated their views were 'not taken into account'. Overall, in both samples the mean decision-regret reported amongst men who indicated their views were 'definitely' taken into account was lower than for men whose views were given less consideration by clinicians (survey-only: 11.4 vs. 25.5 ; interview: 11.4 vs. 29.6 ).

\subsection{INTERVIEWS}

\subsubsection{Comparing survey and interview data}

We compared the responses of individual participants to the survey TDM question with how men later described the process during interviews. Of the 67 men who indicated in the survey their views were 'definitely' taken into account, 12 described during subsequent interviews concerns with the TDM process and thought they had not been adequately involved (Table 3). Of the 26 men who indicated in the survey their views were only taken into account 'to some extent' or 'were not taken into account', almost half $(n=12)$ reflected in their subsequent interview they were content with limited TDM involvement, while just over half $(n=14)$ were not. 


\subsubsection{Factors associated with treatment decisions}

Several factors were identified in the interview data that shaped the TDM process, which have been categorised into three overarching themes: contextual; drivers, and; facilitators.

\subsubsection{Contextual factors}

Contextual factors structured the decision-making process and determined the treatment options available to men, shaping the potential for empowerment. Chief amongst these factors was the way in which men understood the stage of their disease and treatments available.

He (urologist) told me what options there were and I asked, you know, was there any option of doing nothing? And he said: no, your cancer needs treatment and so you've really got to decide, you know, which way you want to go. And I was satisfied there were two treatments that stood a good chance of being successful.

(66 years, Stage III, RP: TDM1, DRS 45)

Comorbidities and previous medical history influenced available options, and while one man understood his irritable bowel syndrome precluded surgery, another described how adhesions from previous abdominal surgery ruled out both surgery and radiotherapy. Men with prior knowledge of cancer or clinical backgrounds better understood available treatment options and side effects, finding it easier to participate in TDM. Locally available treatment options varied and men in rural areas especially and Northern Ireland reported limited access to robotic prostatectomy, brachytherapy and newer treatments.

\subsubsection{Driver factors}

Driver factors represented men's specific preferences with regards both their involvement in the TDM process and for specific treatments. These factors were closely related to an intra-personal process men underwent in adapting and responding to their new situation. It was apparent that for many men the prospect of having to decide their cancer treatment was complex, onerous and 'very, 
very difficult for an ordinary guy', in what was described by one as 'the most stressful stage' of his treatment journey. Many men stated they had wanted more direction from clinicians, and several said they found it 'odd' and 'daunting' to be expected to choose their own treatment, given no clinical knowledge; some asking how they could ever know whether they made the right decision.

I was annoyed that I wasn't advised the best treatment, [and] that I had to decide. The decision should have been made for me in the best treatment and for me to go in and [the consultant] say, right this is the treatment you are going to get, rather than being asked what treatment I would prefer. So I don't know whether it's been the right treatment or not.

$$
\text { (74 years, Stage II, EBRT + ADT: TDM2; DRS missing) }
$$

Indeed, many more study participants indicated they would have preferred greater clinician direction than wanted more autonomy. Some men wanted only to be consulted about treatments clinicians favoured, and be fully informed about potential side effects (/ accepted [the treatment] because that was what the doctor recommended. I was happy with that). Nevertheless, while for some men involvement in the TDM process was unwelcome, others reported taking control of treatment decisions increased psychological well-being.

I'm sort of quite at peace with this [decision] at the moment, as a result of the fact that I feel I've taken as much control of this [TDM process] as I can, by accessing what I consider to be good quality services. ... [It] has been probably the most positive part of my experience so far. (58 years, Stage I, EBRT+ADT: TDM 2; DRS 0)

Other driver factors informed patient's specific treatment preferences. These included the patient's priorities with regards work, social life and HRQoL and the relative intrusiveness of treatments, previous experience of family/friends with particular treatments, and expected treatment sideeffects. The most common Drivers for surgery were an apparent visceral desire to 'get rid of the cancer', that as a treatment modality it was quickly completed, or left open opportunities for further treatments, such as radiotherapy. The most common driver for either radiotherapy or brachytherapy 
was a perception it was less 'intrusive' or 'invasive'. Active surveillance, often interchangeably described as 'watch \& wait', 'wait \& see' or 'active monitoring' was favoured when patients preferred to 'let sleeping dogs lie', believed 'the cure could be worse than the disease', or were simply undecided: 'I'll stick with just the monitoring as I'm not sure what treatment is best.'

\subsubsection{Facilitator factors}

Facilitating factors were those associated with an inter-personal dimension of communication and SDM-between clinicians, men and their partners. Facilitating factors could empower men to make informed treatment decisions that incorporated their preferences and priorities. Facilitators included availability of easily understood information about treatment options, potential side-effects and their likely severity and a few men mentioned treatment decision aids, such as DVDs.

I got quite a lot of information from the hospital on diagnosis and stuff which was very useful, very, very comprehensive explanation, sharing information, discussing the pros and cons of surgery and any other interventions. (54 years, Stage I, RP: TDM1; DRS 0)

Facilitators that enabled men to fulfil their optimum information needs included access to specialist staff, an environment in which men did not feel rushed by clinicians eager for them to make decisions, and access to the lived experience of men who had previously experienced treatments. Partners, where involved, were valued for their role as a 'sounding board' for men to discuss treatment options, and often took responsibility for researching options. However, many of the concerns regarding TDM raised by men in the study concerned an absence of facilitators. In particular, men who were unhappy with the TDM process frequently described not being fully informed of potential treatment effects, and were thus unprepared to manage them.

I wasn't prepared at all. I wasn't. I just thought it was, you know, it will be done and everything will be OK. ... I think I made the wrong decision definitely. I think there should be a lot more explanation of, you know, what's actually happening and what can happen before 
you're actually having your surgery or you've had your radio treatment, whatever, it should be explained a lot, a bit clearer. Not just a pamphlet and say, 'Read that'. You should be sat down and said 'This is what can happen'.

(63 years, Stage II, RP: TDM4, DRS 95)

\subsubsection{Conflicts between TDM factors}

Conflicts that inhibited expression of men's preferences and priorities (drivers) limited autonomy, while conflicts that inhibited communication and knowledge sharing (facilitators) reduced men's ability to make informed decisions. Contextual factors inhibited drivers when particular patient priorities or preferences for certain treatments, often influenced by previous experiences of friends or family, were hindered by their limited availability.

Given experiences of people I know I was told that radiotherapy had quite an adverse effect on you so that's the reason why I was opting for surgery. However, ...the surgeon who did the keyhole surgery had moved...back to England and the only surgeon that I spoke to said that keyhole surgery was not an option over here [N Ireland] now plus the fact that it was open surgery which would have quite serious consequences for a man of my age, so then that's when I opted for radiotherapy. $\quad$ (70 years, Stage I, EBRT: TDM 1; DRS 20)

Drivers and facilitating factors conflicted when a man's preference for delegating TDM to clinicians (driver) was overruled by being reportedly expected to take the lead in TDM, with potential consequences for men's emotional wellbeing.

'The problem is I've asked them [clinicians] about treatments and the best treatment and they haven't been able to give me an answer. ... They say it's up to me to decide which treatment I want. Unfortunately, because I'm not qualified in that area I can't give an opinion on that, so I'm a bit in limbo [about] which is the best treatment. ... I'm very, very depressed about it.'

(67 years, stage I, AS: TDM2; DRS 30) 
Being provided only with facts about treatments and then expected to decide was insufficient for many men to be comfortable in their treatment decision, and specific recommendations were frequently requested from clinicians. When one clinician would not provide a man with a treatment recommendation, he described any choice he made as a 'gamble'.

'I was given the facts of the thing and I said: if you were sitting where I'm sitting, the doctor, and I was sitting where you were sitting, what would your advice be? He said: it's not me, it's you. He wouldn't commit himself so the way it ended up, I had to make the decision.'

(79 years, stage I, EBRT+ADT: TDM1; DRS 30)

Whether or not men wanted TDM responsibility, conflicting clinical advice about appropriate treatment options frequently left them confused rather than empowered.

'One [consultant] was very much open it up, get rid of it and cut it out and then you know it's gone, ... and the other was more gentle and he said well actually, radiotherapy has a pretty high success rate and in your case I don't think there's any need for surgery. .... That's how it was, being passed from one consultant to another.'

(69 years, stage I, EBRT+ADT: TDM1; DRS 30)

Drivers could be compromised retrospectively by an apparent failure of facilitators when men who had completed treatment described becoming aware of treatment options additional to those offered to them. These treatments may not have been appropriate, but the possibility they may have been but were not discussed during TDM added to men's uncertainty. In contrast, one man's strong unchecked treatment preference led him to have surgery, despite clinical advice to remain on AS, and he reported significant subsequent decision regret when treatment side-effects were more severe than expected.

\section{DISCUSSION AND CONCLUSION}




\subsection{Discussion}

This study categorised the primary factors that shaped the TDM process of men diagnosed with localised and locally advanced PCa, in a cross-sectional UK-wide sample. The mixed-methods approach allowed a nuanced understanding of the way in which men viewed their actual and preferred TDM involvement, and their associated levels of decision-regret. Some men desired less involvement, though some then regretted treatment effects, others reported their views were 'definitely' taken into account but nevertheless identified concerns with the TDM process. Men's accounts indicated the way in which clinicians communicated with them could either inhibit their preferences for TDM delegation or leave them confused with conflicting recommendations. Many of the themes identified here resonate with findings reported in previous studies[17]. Recent systematic reviews have synthesised qualitative research on men's use of information to make decisions about PCa treatment options[18], and how couples approach TDM[19]. Previous research in PCa has investigated the influence on TDM of previous family and friends' experience of PCa[20], personal history factors[21], psychological factors[22], patient priorities for treatment decisions[23], treatment-related beliefs[24], and personality traits[25].

A full spectrum of patient involvement with TDM was reflected by study participants, from passive acceptance of paternalistic clinical decisions to adoption of an agency model whereby clinicians educate patients who then make decisions alone. Study participants expressed different preferences for TDM responsibility, but while policy states clinicians should elicit the level of TDM involvement patients want[26,27], a sizable proportion of study participants reported they had been expected to take more responsibility than desired. Arguably, men may have not received sufficient information prior to TDM involvement, and evidence indicates patients have limited knowledge of cancer prior to diagnosis[28]. The survey question did not elicit data on how well informed men were prior to TDM involvement, but previous evidence indicates preference for TDM involvement increases the more individuals are informed[28]. Clinicians frequently underestimate the amount of information 
patients want[17], and may sometimes expect them to engage in TDM prematurely. It is therefore essential, once patients' initial information needs are met, for clinicians to elicit their desired level of TDM involvement.

$\underline{\text { However, }}$ some men may prefer less information on treatment options if they have already established a preference[29], while others may only wish to be 'consulted' on treatment decisions already favoured by clinicians. If patient empowerment involves patients setting strategies to achieve their own goals, then a preference to delegate TDM responsibility does not necessarily entail disempowerment[30]; rather it represents an 'autonomous choice of dependency'[31]. Indeed, requiring patients to take more TDM responsibility than they desire may be to disempower them. Recent evidence indicates incongruence between preferred and actual roles in TDM led to significantly lower health-related quality of life amongst PCa survivors, especially amongst men who reported more involvement than desired[32].

Clinicians' recommendations remain the most consistent factor influencing patients' TDM[22], and many more of our study participants indicated they would have preferred greater clinician direction than wanted more autonomy. However, some patients doubt the objectivity of information received from physicians and want validation from other clinicians[18]. Men wanting active TDM involvement were empowered by adequate facilitating factors, such as easily understandable information and good communication with clinicians[33], which is tailored to their individual preferences for TDM involvement. This would be facilitated via routine use of patient decision aids[28].

Men were potentially disempowered when information was absent[34], or when they received conflicting treatment recommendations. In particular, our findings highlighted the importance of patient preparation for potential side effects, and their possible severity, as a fundamental prerequisite for participating in TDM for PCa. The involvement of partners as information seekers and synthesisers was important, especially given patients forget between $40-80 \%$ of information given during consultations[35]. While men may feel empowered when making decisions based upon 
certain drivers for treatment choice, they sometimes later regretted decisions if clinical advice (facilitating factor) indicating their choice might be inappropriate was ignored. Previous studies have found approximately $16 \%$ of participants expressed regret regarding their PCa treatment choice[30], and if side effects are severe, men may regret their choice whether or not they were actively involved in TDM[30]. Nevertheless, higher levels of decision-regret are significantly associated with higher levels of decisional conflict[36], which might be caused by an absence of facilitators, or receiving conflicting treatment recommendations from clinicians, or being expected to take more TDM responsibility than desired.

\subsection{Limitations}

This is a retrospective study, 2-3 years following PCa diagnosis, and recall bias may be present. Potential interviewer bias was mitigated with use of open-ended questions.

\subsection{Conclusions}

This study identified ways in which the interaction between three categories of factors, context, drivers and facilitators, can enhance or inhibit mens' experience of TDM involvement following a PCa diagnosis. Patient-centred care requires men to be free to articulate and enact their preferences and priorities. For clinicians to effectively facilitate IDM involvement they should acknowledge men's preferences and provide tailored clinical information. TDM failed when men were unable to exercise preferences and priorities or clinicians failed to adequately facilitate them.

\subsection{Practice implications}

The TDM process has potential long-term impact on the HRQoL of men diagnosed with PCa, but men differ in the level of TDM involvement they want. Men should therefore have the opportunity to be informed of exactly which appropriate treatment options are available and why others are not, and the prevalence and potential severity of associated side effects. Use of patient decision aids should be encouraged. However, some men desire greater direction from clinicians about the most 
appropriate treatments, and where possible this should be respected. Expecting men to take greater TDM responsibility than desired can for some men inhibit rather than facilitate patient empowerment. All clinicians involved in a patient's care should be cognizant of each other's views and ensure patients do not receive conflicting recommendations. Men with firm treatment preferences should be encouraged to discuss these with clinicians to prevent potential subsequent decision regret.

\section{Funding statement}

The Life After Prostate Cancer Diagnosis study was funded by the Movember Foundation, in partnership with Prostate Cancer UK, as part of the Prostate Cancer Outcomes programme, grant number BO26/MO. 


\section{References}

1. Cancer Research UK. Cancer Statistics. (http://www.cancerresearchuk.org/healthprofessional/cancer-statistics/statistics-by-cancer-type/prostate-cancer\#heading-Five (Accessed 09/08/17).

2. S. Loeb, M.A. Bjurlin, J. Nicholson, T.L Tammela, D.F. Penson, H.B. Carter, P. Carroll, R. Etzioni, Overdiagnosis and overtreatment of prostate cancer, Eur Urol. 65 (2014) 1046-1055.

3. J.A. Lane, F.C. Hamdy FC, R.M. Martin, E.L. Turner, D.E Neal, J.L. Donovan, Latest results from the UK trials evaluating prostate cancer screening and treatment: the CAP and ProtecT studies, Eur J Cancer. 46 (2010) 3095-101.

4. A.T. Gavin, F.J Drummond, C. Donnelly, E. O'leary, L. Sharp, H.R. Kinnear, Patient reported 'ever had' and 'current' long-term physical symptoms after prostate cancer treatments, BJU Int. 116 (2015) 397-406.

5. U.S. Lehto, H. Tenhola, K. Taari, A. Aromaa, A, Patients' perceptions of the negative effects following different prostate cancer treatments and the impact on psychological well-being: a nationwide survey, Br J Cancer. 116 (2017) 864-873.

6. D.F Penson, M. Rossignol, A.O. Sartor, P.T. Scardino, L.L. Abenhaim, Prostate cancer: epidemiology and health-related quality of life, Urol. 72(6) (2008) S3-S11.

7. G. Carter, K. Clover, B. Britton, A.J. Mitchell, M. White, N. McLeod, J. Denham, S.D. Lambert, Wellbeing during Active Surveillance for localised prostate cancer: A systematic review of psychological morbidity and quality of life, Cancer Treat Rev. 41 (2015) 46-60.

8. L. Klotz, D. Vesprini, P. Sethukavalan, V, Jethava, L. Zhang, S. Jain, T. Yamamoto, A. Mamedov, A. Loblaw, Long-term follow-up of a large active surveillance cohort of patients with prostate cancer, J Clin Oncol. 33 (2014) 272-277.

9. A. Downing, P. Wright, R. Wagland, E Watson, T. Kearney, R. Mottram, M. Allen, V. Cairnduff, O. McSorley, H. Butcher, L Hounsome, C. Donnelly, P. Selby, P. Kind, W. Cross, J.W.H. Catto, D. Huws, D.H. Brewster, E. McNair, L. Matheson, C. Rivas, J. Nayoan, M. Horton, J. Corner, J. Verne, A. Gavin, A.W. Glaser, Life after prostate cancer diagnosis: protocol for a UK-wide patient-reported outcomes study, BMJ open. 6 (2016) e013555. 
10. C. Jenkinson, A. Coulter, S. Bruster, The Picker Patient Experience Questionnaire: development and validation using data from in-patient surveys in five countries. Int J Qual Health Care. 14(5) (2002) 353-358, https://doi.org/10.1093/intqhc/14.5.353

11. Quality Health. National Cancer Patient Experience Survey. https://www.qualityhealth.co.uk/surveys/national-cancer-patient-experience-survey

12. J.C. Brehaut, A.M. O'Connor, T.J. Wood, T.F. Hack, L. Siminoff, E. Gordon, D. FeldmanStewart, Validation of a decision regret scale. Med Decis Making, 23(4) (2003) 281-92.

13. C. Rivas, L. Mattheson, J. Nayoan, A. Glaser, P. Wright, A. Gavin, E. Watson, R. Wagland, Men's transformations following a prostate cancer diagnosis and opportunities for interventions: a meta-ethnography, (unpublished).

14. QSR International Pty Ltd, 2012.

15. J. Ritchie, J. Lewis, Qualitative research practice: a guide for social science students and researchers. Sage, London, 2003.

16. N.K. Gale, G. Heath, E. Cameron, S. Rashid, S. Redwood, Using the framework method for the analysis of qualitative data in multi-disciplinary health research, BMC Med Res Methodol. $13(2013) 117$.

17. R. Say, M. Murtagh, R. Thomson, Patients' preference for involvement in medical decision making: a narrative review, Patient Educ Couns. 60 (2006) 102-114.

18. S. Kandasamy, A.F. Khalid, U. Majid, M. Vanstone, Prostate Cancer Patient Perspectives on the Use of Information in Treatment Decision-Making: A Systematic Review and Qualitative Meta-synthesis, Ont Health Technol Assess Ser. 17 (2017) 1-30.

19. K. Schumm, Z. Skea, L. McKee, J. Dow, 'They're doing surgery on two people': a meta ethnography of the influences on couples' treatment decision making for prostate cancer, Health Expect. 13 (2010) 335-349.

20. J. Xu, A.V. Neale, R.K. Dailey, S. Eggly, K.L. Schwartz, Patient perspective on watchful waiting/active surveillance for localized prostate cancer, J Am Board Fam Med. 25 (2012) 763-770.

21. D.L. Berry, W.J. Ellis, N.F. Woods, C. Schwien, K.H. Mullen, C. Yang, Treatment decisionmaking by men with localized prostate cancer: the influence of personal factors, Urol Oncol. 21 (2003) 93-100. 
22. F. Wong, D.E. Stewart, J. Dancey, M. Meana, M.P. McAndrews, T. Bunston, A.M. Cheung, Men with prostate cancer: influence of psychological factors on informational needs and decision making, J Psychosom Res. 49 (2000) 13-19.

23. C.K. Gwede, J. Pow-Sang, J. Seigne, R. Heysek, M. Helal, K. Shade, A. Cantor, P.B. Jacobsen, Treatment decision-making strategies and influences in patients with localized prostate carcinoma, Cancer. 104 (2005) 1381-1390.

24. M.A. Diefenbach, J. Dorsey, R.G. Uzzo, G.E. Hanks, R.E. Greenberg, E. Horwitz, F. Newton, P.F. Engstrom, Decision-making strategies for patients with localized prostate cancer, Semin Urol Oncol. 20 (2002) 55-62.

25. L.M. Wenger, J.L. Oliffe, Men managing cancer: a gender analysis, Sociol Health IIIn. 36 (2014) 108-22.

26. NICE (2012) Prostate cancer: diagnosis and management. https://www.nice.org.uk/guidance/cg175 (Accessed 20/04/17)

27. NICE (2012) Improving outcomes in urological cancers. Cancer Service guideline [CSG2] https://www.nice.org.uk/guidance/csg2 (Accessed 20/04/2017).

28. G.A. Lin, D.S. Aaronson, S.J. Knight, P.R. Carroll, R.A. Dudley, Patient decision aids for prostate cancer treatment: a systematic review of the literature, CA Cancer J Clin. 59 (2009) 379-390.

29. L.W. Mroz, J.L. Oliffe, B.J. Davison, Masculinities and patient perspectives of communication about active surveillance for prostate cancer, Health Psychol. 32 (2013) 83-90.

30. R.M. Anderson, M.M. Funnell, P.A. Barr, R.F. Dedrick, W.K. Davis, Learning to Empower Patients: Results of Professional Education Program for Diabetes Educators, Diabetes Care. 14 (1991) 584-590.

31. P. N. Butow, M. Maclean, S. M. Dunn, M. H. N. Tattersall, M. J. Boyer, The dynamics of change: Cancer patients' preferences for information, involvement and support, Ann Oncol. 8 (1997) 857-863.

32. F.J. Drummond, A.T. Gavin, L. Sharp, Incongruence in treatment decision making is associated with lower health-related quality of life among prostate cancer survivors: results from the PiCTure study, Supp Care Cancer. 26 (2018) 1645-1654. 
33. P. Bravo, A. Edwards, P.J. Barr, I. Scholl, G. Elwyn, M. McAllister, Conceptualising patient empowerment: a mixed methods study, BMC Health Serv Res. 15 (2015) 252.

34. M. Edwards, F. Wood, M. Davies, A. Edwards, The development of health literacy in patients with a long-term health condition: the health literacy pathway model, BMC Public Health. 12 (2012) 130.

35. R.P. Kessels, Patients' memory for medical information, J R Soc Med. 96 (2003) 219-222.

36. T.D. Denberg, T.V. Melhado, J.F. Steiner, Patient treatment preferences in localized prostate carcinoma: the influence of emotion, misconception, and anecdote, Cancer. 107 (2006) 620630. 
Table 1: Demographic and treatment characteristics of surveyed and interviewed men

\begin{tabular}{|c|c|c|c|}
\hline Characteristic & & $\begin{array}{c}\text { Survey } \\
(n=26,808,100 \%)\end{array}$ & $\begin{array}{c}\text { Interviews } \\
(n=97,100 \%)\end{array}$ \\
\hline Age & Mean (range) & $71.09(41-98)$ years & $65.5(48-87)$ years \\
\hline \multirow{4}{*}{ Nation } & England & $23,001(85.8 \%)$ & $71(78.0 \%)$ \\
\hline & Wales & $1,861(6.9 \%)$ & $10(10.3 \%)$ \\
\hline & Scotland & $1,103(4.1 \%)$ & $6(6.2 \%)$ \\
\hline & Northern Ireland & $843(3.1 \%)$ & $10(10.3 \%)$ \\
\hline \multirow[t]{3}{*}{ Disease stage } & 1 & $10,880(30.4 \%)$ & $45(46.4 \%)$ \\
\hline & II & $8,719(24.3 \%)$ & $28(28.9 \%)$ \\
\hline & III & $7,209(26.9 \%)$ & $24(24.5 \%)$ \\
\hline \multirow[t]{5}{*}{ Marital Status } & Married/ Civil partnership & $21,187(80.0 \%)$ & $68(70.1 \%)$ \\
\hline & Separated/Divorced & $1,970(7.4)$ & $6(6.2 \%)$ \\
\hline & Widowed & $1,946(7.4 \%)$ & $2(2.1 \%)$ \\
\hline & Single & $1,023(3.9 \%)$ & $12(12.4 \%)$ \\
\hline & Other & $358(1.4 \%)$ & $9(9.2 \%)$ \\
\hline \multirow[t]{4}{*}{ Sexual Orientation } & Heterosexual & 24,966 (93.1\%) & $83(85.6 \%)$ \\
\hline & Homosexual & $213(0.8 \%)$ & $13(13.4 \%)$ \\
\hline & Other & $526(2.0 \%)$ & $0(0.0 \%)$ \\
\hline & Missing & $1,103(4.1 \%)$ & $1(1.0 \%)$ \\
\hline \multirow[t]{3}{*}{ Ethnicity } & White & $25,180(96.8 \%)$ & $87(89.6 \%)$ \\
\hline & Black British & $410(1.6 \%)$ & $9(10.3 \%)$ \\
\hline & Other & $413(1.6 \%)$ & $1(2.1 \%)$ \\
\hline \multirow[t]{7}{*}{ Treatment } & EBRT + ADT & $6,047(26.7 \%)$ & $26(25.2 \%)$ \\
\hline & Active surveillance & $2,399(10.6 \%)$ & $25(24.3 \%)$ \\
\hline & Surgery only & $5,929(26.1 \%)$ & $23(23.7 \%)$ \\
\hline & ADT Only & $1,452(6.4 \%)$ & $6(6.2 \%)$ \\
\hline & EBRT only & 2,106 (9.3\%) & $5(5.2 \%)$ \\
\hline & Surgery + EBRT/ADT & $1,654(7.3 \%)$ & $6(6.2 \%)$ \\
\hline & Other & $4450(16.6 \%)$ & $6(6.2 \%)$ \\
\hline
\end{tabular}

Overall survey \%s relate to proportion of men at stage I, II or III. An additional 3,925 men had stage IV disease at diagnosis and 5,090 were missing stage at diagnosis information from cancer registration records. 'Other treatment' includes systemic treatments, HIFU, unknown radiotherapy, follow-up unknown, no treatment or other combination not otherwise listed. 'Other sexuality' includes bisexual, don't know and prefer not to answer. 'Other marital status' was left up to men to determine, but included in the interview sample men who had partners who were not married or in a civil partnership.

EBRT External Beam Radiotherapy; ADT Androgen deprivation therapy. 
Table 2: Survey responses of surveyed and interviewed men to involvement in TDM question and Decision Regret Score:

\begin{tabular}{|c|c|c|c|c|c|c|c|c|c|c|c|}
\hline \multicolumn{2}{|c|}{ Question Items } & \multicolumn{2}{|c|}{ 'Yes, definitely' } & \multicolumn{2}{|c|}{ 'Yes, to some extent' } & \multicolumn{2}{|c|}{$\begin{array}{c}\text { 'No, my views were } \\
\text { not taken into } \\
\text { account' }\end{array}$} & \multicolumn{2}{|c|}{$\begin{array}{l}\text { 'Didn't know treatment } \\
\text { was being discussed' }\end{array}$} & \multicolumn{2}{|c|}{ 'Not sure' } \\
\hline & & Survey & Interviews & Survey & Interviews & Survey & Interviews & Survey & Interviews & Survey & Interviews \\
\hline $\begin{array}{l}\text { TDM } \\
\text { Involvement }\end{array}$ & $\begin{array}{l}\text { No. men } \\
(\%)\end{array}$ & $\begin{array}{l}18,907 \\
(68.8)\end{array}$ & $\begin{array}{l}67 \\
(69.0)\end{array}$ & $\begin{array}{l}4,670 \\
(17.8)\end{array}$ & $\begin{array}{l}24 \\
(24.7)\end{array}$ & $\begin{array}{l}879 \\
(3.3)\end{array}$ & $\begin{array}{l}2 \\
(2.1)\end{array}$ & $\begin{array}{l}877 \\
(3.3)\end{array}$ & $\begin{array}{l}3 \\
(3.0)\end{array}$ & $\begin{array}{l}909 \\
(3.5)\end{array}$ & $0(0.0)$ \\
\hline \multirow[t]{3}{*}{$\begin{array}{l}\text { Decision } \\
\text { Regret Score }\end{array}$} & $\begin{array}{l}\text { Mean } \\
\text { (SD) }\end{array}$ & $\begin{array}{l}11.4 \\
(14.2) \\
\end{array}$ & $\begin{array}{l}11.4 \\
(15.2) \\
\end{array}$ & $\begin{array}{l}25.5 \\
(18.4) \\
\end{array}$ & $\begin{array}{l}29.6 \\
(20.7) \\
\end{array}$ & $\begin{array}{l}31.9 \\
(23.6)\end{array}$ & $\begin{array}{l}37.5 \\
(53.0) \\
\end{array}$ & $\begin{array}{l}27.5 \\
(20.1)\end{array}$ & $\begin{array}{l}58.3 \\
(33.3) \\
\end{array}$ & $\begin{array}{l}25.7 \\
(18.3)\end{array}$ & $0(0.0)$ \\
\hline & $\begin{array}{l}\text { Median } \\
\text { (IQR) }\end{array}$ & $\begin{array}{l}5 \\
(0-20)\end{array}$ & $\begin{array}{l}5 \\
(0-20)\end{array}$ & $\begin{array}{l}25 \\
(10-35)\end{array}$ & $\begin{array}{l}32.5 \\
(10-40)\end{array}$ & $\begin{array}{l}30 \\
(15-50)\end{array}$ & $\begin{array}{l}37.5 \\
(0-75) \\
\end{array}$ & $\begin{array}{l}25 \\
(10-40)\end{array}$ & $\begin{array}{l}50 \\
(30-50)\end{array}$ & $\begin{array}{l}25 \\
(10-40)\end{array}$ & $0(0.0)$ \\
\hline & Range & $0-100$ & $0-80$ & $0-100$ & $0-65$ & $0-100$ & $0-75$ & $0-100$ & $30-95$ & $0-100$ & $0(0.0)$ \\
\hline
\end{tabular}

Survey $n=26,291$ men completing the TDM question (98.1\% of respondents at stage I-III). Interview $n=97$ men

SD Standard Deviation. IQR Inter quartile range. 
Table 3: Retrospective reasons given in interviews for lack of decision-making satisfaction amongst men who had indicated in the survey their views had 'definitely' been taken into account

\begin{tabular}{|l|l|l|c|c|c|c|}
\hline Pt No. & Stage & \multicolumn{1}{|c|}{ Tx } & $\begin{array}{c}\text { Lack of info } \\
\text { tx 0ptions }\end{array}$ & $\begin{array}{c}\text { Lack of info } \\
\text { side effects }\end{array}$ & $\begin{array}{c}\text { Felt } \\
\text { rushed }\end{array}$ & $\begin{array}{c}\text { No HCP Tx } \\
\text { recommendations }\end{array}$ \\
\hline 1SG02AX09 & 1 & EBRT & $X$ & & & \\
\hline 1SG03AX24 & 1 & ADT/AM & & & & \\
\hline 1SG04AX05 & 1 & AM & $X$ & & & \\
\hline 5SG01BX03 & 1 & RP & & $X$ & & \\
\hline 2SG08XX19 & 1 & AM & $X$ & & & \\
\hline 1SG04BX16 & 2 & ADT & $X$ & & & \\
\hline 1SG04BX28 & 2 & AM & $X$ & $X$ & & $X$ \\
\hline 4SG08XX06 & 2 & RP & & & $X$ & \\
\hline 5SG03B104 & 2 & HT & & $X$ & & $X$ \\
\hline 2SG09XX08 & 3 & RP & $X$ & $X$ & & $X$ \\
\hline 2SG09XX03 & 3 & RP & $X$ & $X$ & $X$ & \\
\hline 1SG03AX26 & 3 & ADT & & & & \\
\hline
\end{tabular}


Table 4: Categorised factors that influence Treatment decision-making (TDM)

\begin{tabular}{|l|l|}
\hline Categories & Themes \\
\hline Contextual factors & How patients understand their condition \\
\cline { 2 - 3 } & Comorbidities and previous medical history \\
\cline { 2 - 3 } & Patient knowledge and understanding of cancer \\
\cline { 2 - 3 } & Geographical availability of treatments \\
\hline Drivers & Preference for involvement in TDM \\
\cline { 2 - 2 } & Priorities for work/ lifestyle \\
\cline { 2 - 2 } & Treatment preferences or 'let sleeping dogs lie' \\
\cline { 2 - 2 } & Previous experience of friends and family \\
\cline { 2 - 2 } & Perception of certain treatments as 'intrusive'/ 'invasive' \\
\hline & Information regarding treatment options \\
\cline { 2 - 2 } & Information regarding treatment side effects (severity/prevalence \\
\cline { 2 - 2 } & Treatment Decision Aids (TDAs) \\
\cline { 2 - 2 } & Involvement of partners \\
\cline { 2 - 2 } & Access to lived experience of previously treated men \\
\cline { 2 - 2 } & Unrushed environment \\
\hline
\end{tabular}

